OPEN ACCESS

Edited by:

Angela Casini,

Cardiff University, United Kingdom

Reviewed by:

Gilles Gasser,

Université de Sciences Lettres de

Paris, France

Tatjana N. Parac-Vogt,

KU Leuven, Belgium

*Correspondence:

Bruno Therrien

bruno.therrien@unine.ch

Specialty section:

This article was submitted to

Supramolecular Chemistry,

a section of the journal

Frontiers in Chemistry

Received: 25 October 2018 Accepted: 20 November 2018 Published: 11 December 2018

Citation:

Therrien B (2018) The Role of the

Second Coordination Sphere in the Biological Activity of Arene Ruthenium

Metalla-Assemblies

Front. Chem. 6:602

doi: $10.3389 /$ fchem.2018.00602

\section{The Role of the Second Coordination Sphere in the Biological Activity of Arene Ruthenium Metalla-Assemblies}

\author{
Bruno Therrien* \\ Institute of Chemistry, University of Neuchatel, Neuchatel, Switzerland
}

For nearly 15 years, the biological and biomedical applications of arene ruthenium metalla-assemblies have flourished. Today, the synthetic strategies to generate arene ruthenium assemblies are well-established, and these compounds offer tremendous possibilities in terms of structural diversities and chemical properties. However, the second coordination sphere is often poorly considered, if not ignored, when designing such arene ruthenium metalla-assemblies. These weak interactions (hydrogen bonding, hydrophobic, ionic, electrostatic, van der Waals, $\pi-\pi$ stacking) that take place in the solid state or in solution are generally key interactions for the foreseen applications. Therefore, in this review, we want to emphasize this important property of arene ruthenium metalla-assemblies by showing examples dealing with second coordination sphere interactions and how this can be better integrated in the design of these versatile supramolecular metal-based entities.

Keywords: arene ruthenium, metalla-assemblies, bio-inorganic, piano-stool complexes, weak interactions, second coordination sphere

\section{INTRODUCTION}

It is now well-known that the second coordination sphere (second shell) plays a major role in metal-based enzymatic transformations (Dudev et al., 2003). These additional interactions that take place in the proximity of the catalytic pocket can either stabilize the metal-substrate complex, stabilize the electronic state of the metal, orient the ligands to enhance the reactivity, act as proton and/or electron mediators, and so on (Ando et al., 1996; Botta, 2000; Steed, 2001; Haviv et al., 2018). More generally, these weak interactions (coordination, ionic, hydrogen bonding, hydrophobic, electrostatic, van der Waals, $\pi-\pi$ stacking) are not only extremely important for biological processes, they are also a pillar of supramolecular chemistry. They allow the formation in the solid state of molecular networks (Hosseini, 2003), the preparation of liquid crystalline materials (Kato et al., 2018), the construction of coordination-driven assemblies (Fujita et al., 2005), as well as the generation of many other supramolecular systems (Wu et al., 2008; Zhou et al., 2017).

For many years, we have been involved in the field of coordination-driven self-assembly, using piano-stool complexes (also called half-sandwich complexes) as building blocks, and especially arene ruthenium complexes as biological agents (Therrien and Furrer, 2014; Therrien, 2015). The piano-stool unit provides three coordination sites at $90^{\circ}$ from each other for a strategic 


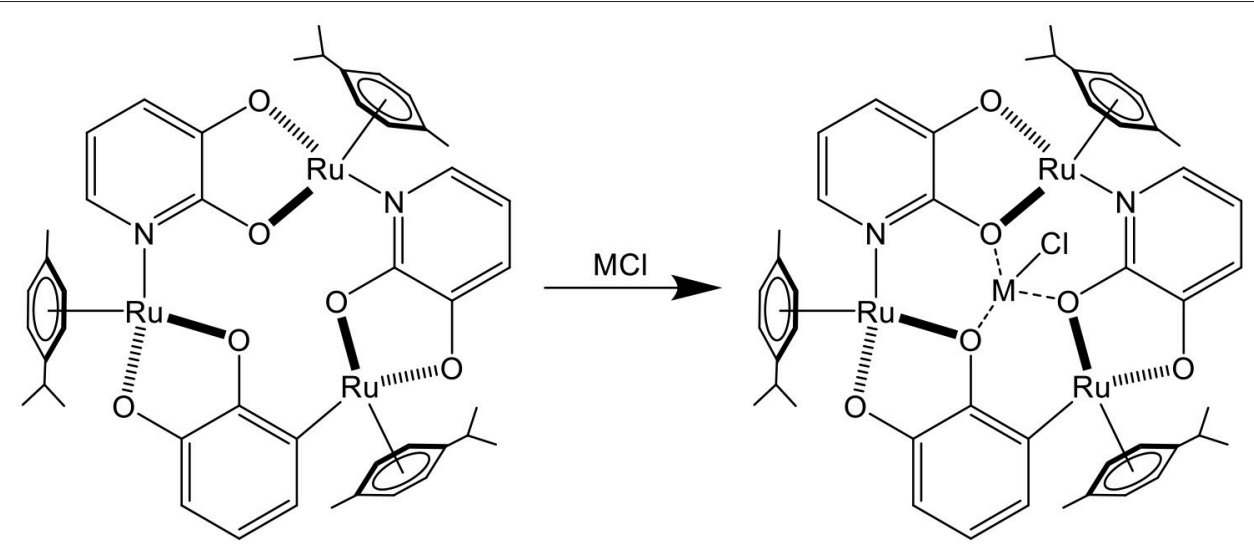

FIGURE 1 | Sensing of $\mathrm{MCl}(\mathrm{M}=\mathrm{Li}, \mathrm{Na}, \mathrm{K})$ in a trinuclear arene ruthenium metalla-cycle (Piotrowski et al., 2001).

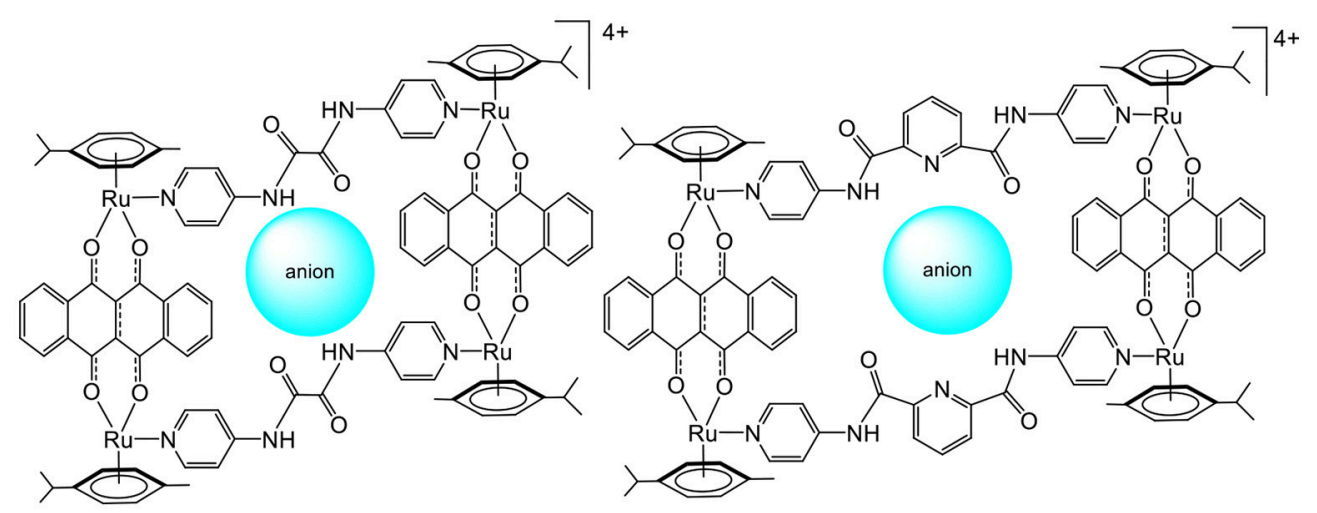

FIGURE 2 | Sensing of polyanionic species in tetranuclear arene ruthenium metalla-assemblies (Vajpayee et al., 2011; Mishra et al., 2012).

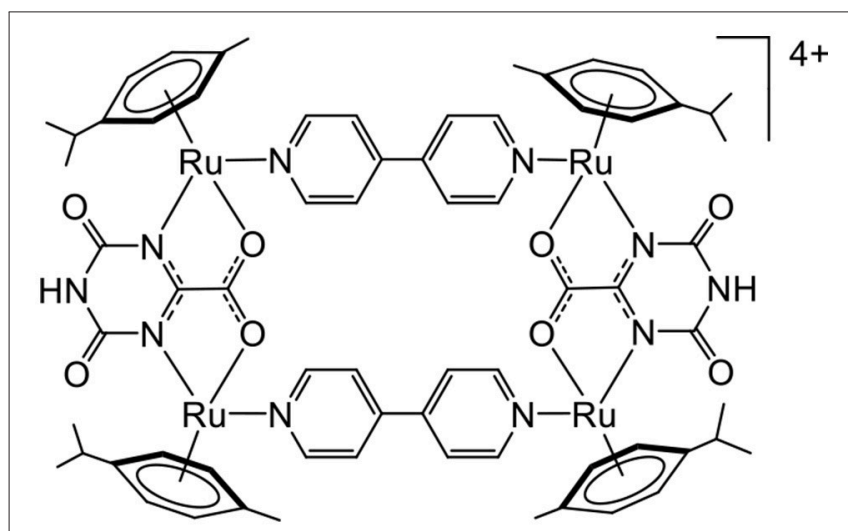

FIGURE 3 | Arene ruthenium metalla-rectangle interacting with DNA (Linares et al., 2009).

coordination of ligands on metals (Therrien, 2009), which allows the design of 2D and 3D entities (Cook et al., 2013; Singh et al., 2014; Therrien, 2018). These metalla-assemblies possess different functional groups, situated either at the periphery or at the core of the assembly. They have good stability in solution, showing no dynamic ligand exchange under ordinary conditions (Garci et al., 2014). They come in different sizes, with or without a cavity, and they can be positively charged, thus showing various properties and solubility. Among these properties, host-guest chemistry, biological activity, DNA interactions, recognition, ion binding, and others have been identified. Therefore, in this perspective review, the biological applications of arene ruthenium metalla-assemblies are discussed from the second coordination sphere point of view, to better emphasize the importance of weak interactions in diverse properties. Ultimately, it can provide to those working in the field a different angle to envision the next generation of metallaassemblies in biomedical fields.

\section{SENSING}

The first example of arene ruthenium metalla-assemblies used for sensing was published in 2001 (Piotrowski et al., 2001). The electrochemical property of a trinuclear arene ruthenium metalla-cycle was exploited. Interestingly, upon the binding of alkali chloride salts in the triple-oxo binding site of the metalla-cycle (Figure 1), the oxidation potential of the trinuclear 
assembly was shifted by as much as $450 \mathrm{mV}$ in the presence of $\mathrm{LiCl}$, thus providing a redox-responsive signal upon guest binding.

Later, the possibility of using arene ruthenium metallaassemblies for sensing biologically relevant substrates was explored by Chi and Stang (Vajpayee et al., 2011; Mishra et al., 2012). The cavity of arene ruthenium metalla-rectangles (Figure 2) has shown interactions with polyanionic compounds (oxalate, citrate, tartrate). The presence of multiple amido and pyridine groups within the core of the metalla-rectangles was crucial for the recognition process to take place. Moreover, the amido groups gave some structural flexibility to the systems, thus providing binding adaptability to optimize the interactions with anions. In these systems, the size of the cavity and the capacity to form several hydrogen-bonds with anions are crucial elements for the sensing process to take place.

These are simple examples in which the nature of the functional groups incorporated in the building blocks of the arene ruthenium metalla-assemblies has provided valuable second sphere coordination interactions to develop metallaassembled sensors.

\section{DNA INTERACTIONS}

The good water solubility and the presence of positive charges on most arene ruthenium metalla-assemblies are both advantageous properties for interactions with biomolecules. The first study dealing with arene ruthenium metallaassemblies and DNA interactions was published in 2009 (Figure 3). The tetracationic bowl-shaped rectangle showed good interaction with calf-thymus DNA (Linares et al., 2009). Binding assays have suggested that the interactions take place in the major groove of the duplex DNA strand. Conformational changes in the DNA strand are probably due to electrostatic interactions between the cationic metalla-rectangle and the negatively charged surface of DNA as well as the good match

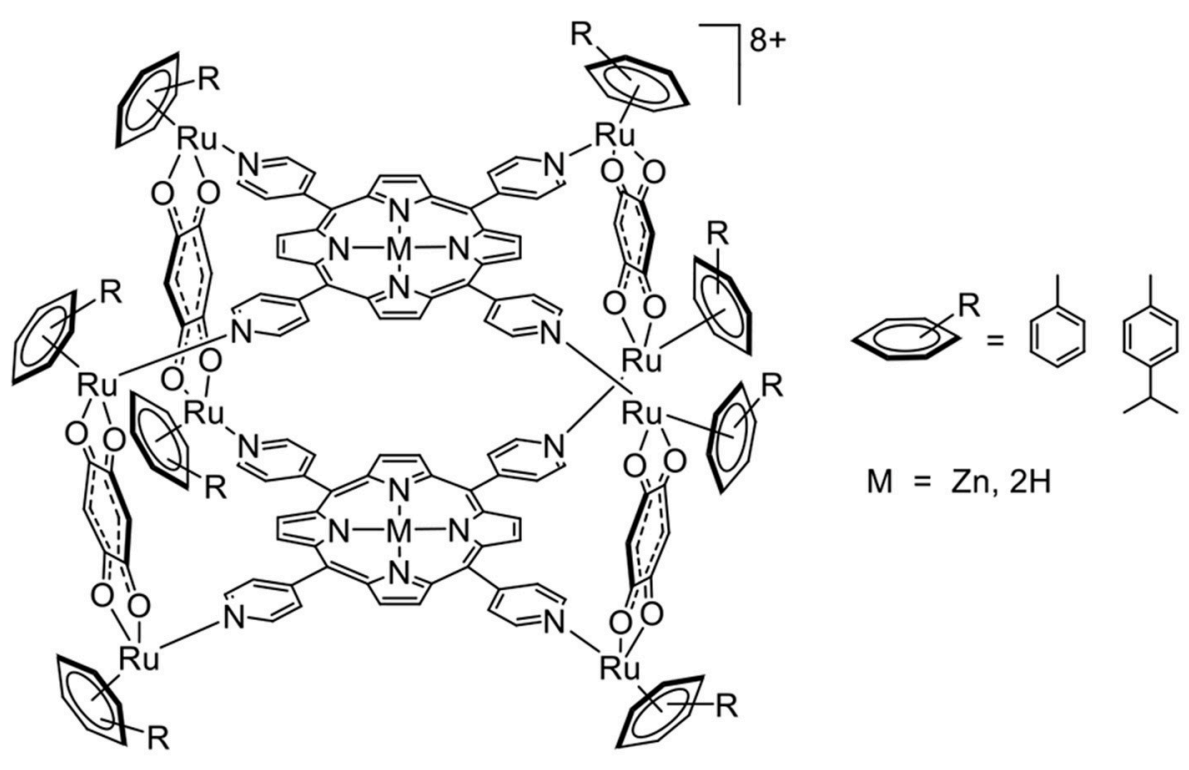

FIGURE 4 | Arene ruthenium metalla-cubes interacting with G-quadruplexes (Barry et al., 2009).

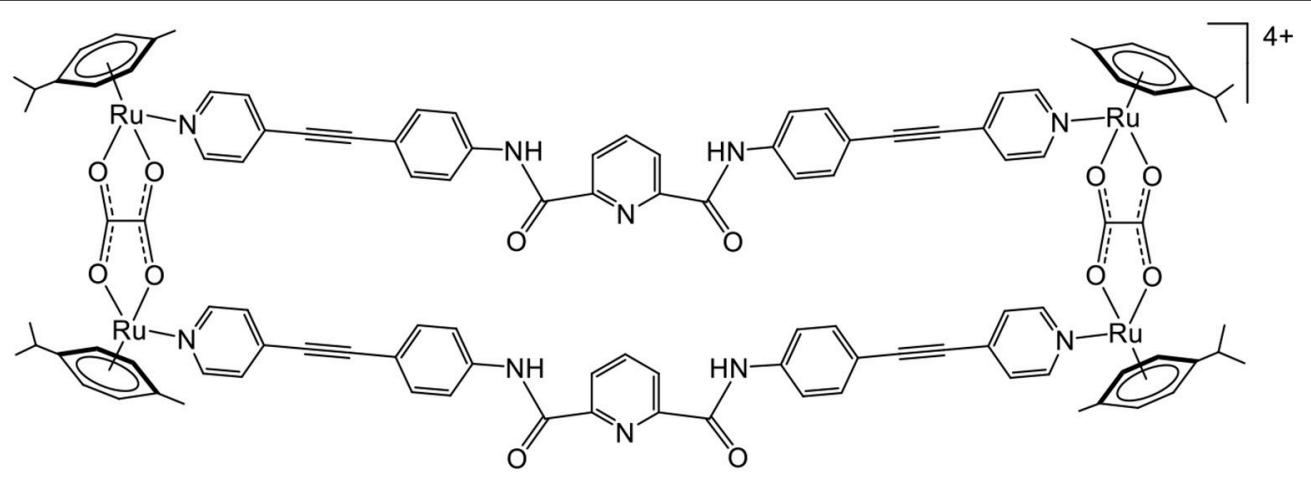

FIGURE 5 | Arene ruthenium metalla-rectangle interacting with EGF protein (Mishra et al., 2014). 
between the size of the rectangle and the size of the major groove.

Following this initial study, several other arene ruthenium metalla-assemblies were tested as duplex DNA binders (Linares et al., 2010; Paul et al., 2015; Gupta et al., 2016, 2017). However, in the human genome, DNA sequences can fold into other thermodynamically stable structures such as hairpins and quadruplexes. These kinds of secondary structures are interesting targets for therapeutic applications (Zhao et al., 2010).

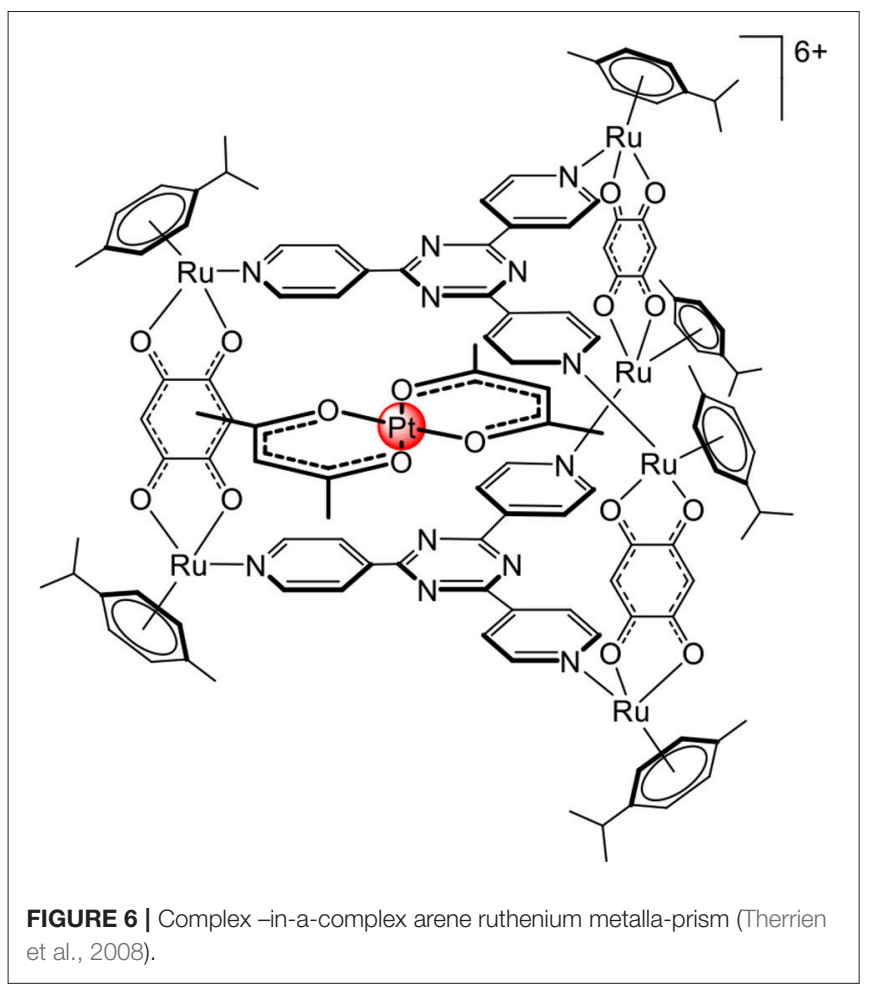

Consequently, arene ruthenium metalla-assemblies have been used, for example, as quadruplex DNA stabilizers (Barry et al., 2009).

A G-quadruplex is composed of guanine tetrads intercalated by cations, and it possesses a planar aromatic surface (Balasubramanian and Neidle, 2009). Therefore, cationic molecules with $\pi$-stacking affinity can potentially interact with G-quadruplexes. This possibility of interaction and stabilization was confirmed from the porphyrin-based arene ruthenium metalla-cubes (Figure 4), which showed good stabilization of telomeric and $c-m y c$ DNA quadruplexes. In such systems, we can assume that a combination of electrostatic and $\pi$-stacking (hydrophobic) interactions generates second coordination sphere interactions.

\section{PROTEIN INTERACTIONS}

Like DNA, proteins can positively interact with cationic compounds, and accordingly with positively charged arene ruthenium metalla-assemblies. Different proteins interacting with such metalla-assemblies have been identified. Interestingly, these studies have shown that metalla-assemblies of different shapes, sizes, structures and numbers of charges are able to interact with proteins, confirming that interaction with biomolecules is a common feature of arene ruthenium metallaassemblies (Dubey et al., 2015; Elumalai et al., 2016, 2017).

Indeed, an arene ruthenium metalla-rectangle with bisamido pyridine containing linkers (Figure 5) shows strong interaction with enhanced green fluorescence protein (EGFP) (Mishra et al., 2014). Similarly, an arene ruthenium metallaprism can disrupt the folded structures of albumin, transferrin, cytochrome-c, and other proteins (Paul et al., 2018), showing a great diversity of protein interactions. These examples

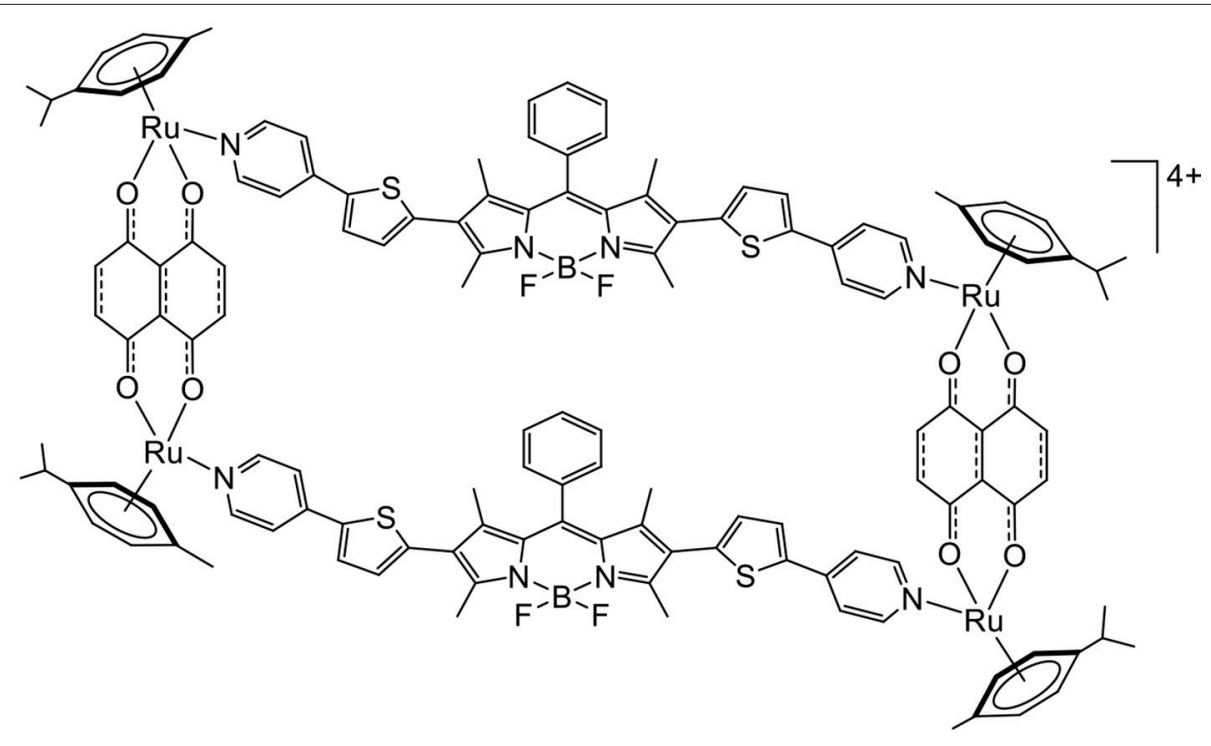

FIGURE 7 | BODIPY-based tetranuclear arene ruthenium metalla-assemblies as potential PDT agent (Gupta et al., 2017). 


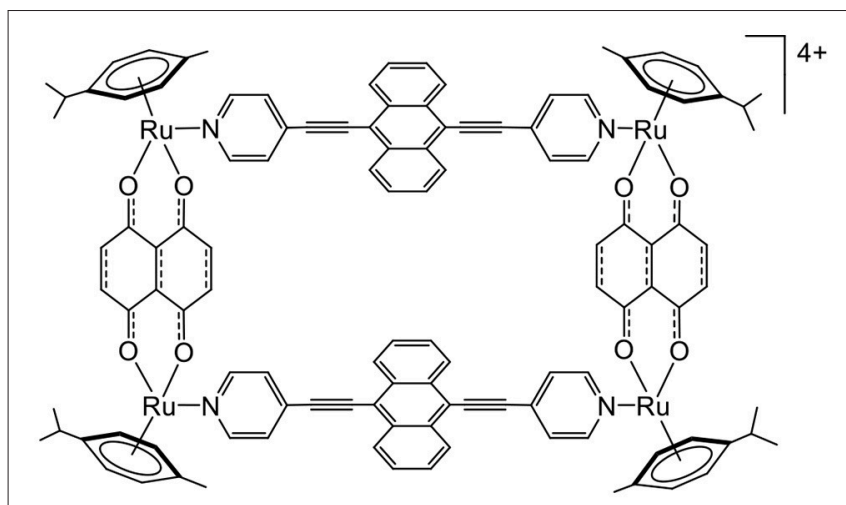

FIGURE 8 | Anthracene-based tetranuclear arene ruthenium metalla-assemblies for $\mathrm{O}_{2}$ interactions (Gaschard et al., 2018).

suggest that the interactions between metalla-assemblies and proteins are mainly electrostatic. Therefore, to optimize the metalla-assembly protein interactions, and to gain a degree of selectivity for a specific protein, one cannot rely purely on electrostatic, hydrophobic, size-dependent or hydrogenbond interactions. Only the multiplicity of second coordination sphere interactions can generate selective protein binders, which increases the complexity of designing arene ruthenium metallaassemblies.

\section{DECOMPLEXATION UPON INTERACTIONS}

The first biological application of arene ruthenium metallaassemblies was confirmed by the complex-in-a-complex system (Figure 6), in which a water-soluble arene ruthenium metallaprism was used to transport the platinum acetylacetonate complex to cells (Therrien et al., 2008). Later, it was demonstrated that, after internalization, the guest complex was released, most likely upon disassembly of the cage compound (Mattsson et al., 2010). Furthermore, the metalla-prism can interact with biomolecules such as arginine, cysteine, glutathione, lysine, histidine (Paul et al., 2012a,b), and biomolecules possessing coordinating functional groups, thus being able to initiate the breakage of the cage compound. This suggests that despite being relatively robust to ligand exchange processes (Garci et al., 2014), second coordination sphere interactions can be used to disassemble arene ruthenium metalla-assemblies.

\section{OXYGEN INTERACTIONS}

In traditional photodynamic therapy (PDT), a photosensitizer interacts with oxygen to produce reactive oxygen species (ROS), and these ROS trigger cell death upon light activation (Patrice et al., 2003). Therefore, to evaluate the potential of using arene ruthenium metalla-assemblies as PDT agents, several metallaassemblies coupled to photosensitizers were prepared and tested (Schmitt et al., 2009). The arene ruthenium units can modulate the solubility of the photosensitizers (Schmitt et al., 2008) as well as modify its photochemical behavior. Moreover, the cavity of arene ruthenium cages can transport and protect the photosensitizer (Schmitt et al., 2012).

Nevertheless, other types of molecules can interact with oxygen to generate ROS. This is the case of BODIPY, an interesting fluorescent dye with a high-quantum yield that can promote the production of ROS. Therefore, BODIPY-based linkers have been recently inserted in arene ruthenium metallarectangles (Figure 7), and the cytotoxicity of the compounds on various cancer cell lines was confirmed (Gupta et al., 2017). The fluorescence associated with the BODIPY units was exploited to localize the metalla-rectangle in the cytoplasm of cancer cells. However, the possibility of using such metalla-rectangles as PDT agents remains to be explored.

Anthracene is another molecule that can react with oxygen (Aubry et al., 2003). Anthracene forms in the presence of oxygen and light activation, an endoperoxide intermediate. The endoperoxide formation is reversible, and oxygen can be released in a different environment. Therefore, knowing that arene ruthenium metalla-assemblies can be internalized to cells and can be coupled to photosensitizers, we have recently synthesized an anthracene-based metalla-rectangle (Figure 8) (Gaschard et al., 2018). Despite an unsuccessful endoperoxide formation on the metalla-rectangle, the ultimate goal of this project was to transport oxygen and a photosensitizer to cells for an optimization of PDT treatments in hypoxic cancers.

\section{CONCLUSION}

As pointed out in this article, the second coordination sphere plays a major role in most biological and biomedical applications involving arene ruthenium metalla-assemblies. Therefore, the introduction of functional groups that can generate weak interactions with biomolecules on either the arene, the building blocks or the guest molecules is essential for the development of biologically active arene ruthenium metalla-assemblies. In the future, designing metalla-assemblies with second coordination sphere interactions in mind will be challenging, but it could provide the next generation of arene ruthenium derivatives for biological and biomedical applications.

\section{AUTHOR CONTRIBUTIONS}

The author confirms being the sole contributor of this work and has approved it for publication.

\section{FUNDING}

Over the years, we would like to acknowledge the financial support from the Swiss National Science Foundation, the European Union (POLYTHEA and NOAH projects) and the University of Neuchatel.

\section{ACKNOWLEDGMENTS}

The author would like to thank past and present members of his group. 


\section{REFERENCES}

Ando, I., Ishimura, D., Ujimoto, K., and Kurihara, H. (1996). Effect of secondsphere coordination. 4. Factors influencing the electrochemical behavior of ruthenium-ammine complexes caused by second-sphere coordination of crown ethers. Inorg. Chem. 35, 3504-3508. doi: 10.1021/ic941048e

Aubry, J.-M., Pierlot, C., Rigaudy, J., and Schmidt, R. (2003). Reversible binding of oxygen to aromatic compounds. Acc. Chem. Res. 36, 668-675. doi: $10.1021 / \mathrm{ar} 010086 \mathrm{~g}$

Balasubramanian, S., and Neidle, S. (2009). G-quadruplex nucleic acids as therapeutic targets. Curr. Opin. Chem. Biol. 13, 345-353. doi: 10.1016/j.cbpa.2009.04.637

Barry, N. P. E., Abd Karim, N. H., Vilar, R., and Therrien, B. (2009). Interactions of ruthenium coordination cubes with DNA. Dalton Trans. 10717-10719. doi: $10.1039 / \mathrm{b} 913642 \mathrm{~h}$

Botta, M. (2000). Second coordination sphere water molecules and relaxivity of gadolinium(III) complexes: implications for MRI contrast agents. Eur. J. Inorg. Chem. 2000, 399-407. doi: 10.1002/(SICI) 1099-0682(200003)2000:3<399::AID-EJIC399>3.0.CO;2-B

Cook, T. R., Vajpayee, V., Lee, M. H., Stang, P. J., and Chi, K.-W. (2013). Biomedical and biochemical applications of self-assembled metallacycles and metallacages. Acc. Chem. Res. 46, 2464-2474. doi: 10.1021/ar400010v

Dubey, A., Park, D. W., Kwon, J. E., Jeong, Y. J., Kim, T., Kim, I., et al. (2015). Investigation of the biological and anti-cancer properties of ellagic acid-encapsulated nano-sized metalla-cages. Int. J. Nanomed. 2015, 227-240. doi: $10.2147 / \mathrm{IJN} . \mathrm{S} 88289$

Dudev, T., Lin, Y.-,-1., Dudev, M., and Lim, C. (2003). First-second shell interactions in metal binding sites in proteins: A PDB survey and DFT/CDM calculations. J. Am. Chem. Soc. 125, 3168-3180. doi: 10.1021/ja0209722

Elumalai, P., Jeong, Y. J., Park, D. W., Kim, D. H., Kim, H., Kang, S. C., et al. (2016). Antitumor and biological investigation of doubly cyclometalated ruthenium(II) organometallics derived from benzimidazolyl derivatives. Dalton Trans. 45, 6667-6673. doi: 10.1039/C5DT04400F

Elumalai, P., Kaushik, N., Kim, D. H., Kim, H., Lee, S. J., Choi, E. H., et al. (2017). Flexible ligated ruthenium(II) self-assemblies sensitizes glioma tumor initiating cells in vitro. Oncotarget 8, 60188-60200. doi: 10.18632/oncotarget.19028

Fujita, M., Tominaga, M., Hori, A., and Therrien, B. (2005). Coordination assemblies from a $\mathrm{Pd}(\mathrm{II})$-cornered square complex. Acc. Chem. Res. 38, 371-380. doi: 10.1021/ar040153h

Garci, A., Marti, S., Schürch, S., and Therrien, B. (2014). Insight into the dynamic ligand exchange process involved in bipyridyl linked arene ruthenium metallarectangles. RSC Adv. 4, 8597-8604. doi: 10.1039/c3ra46859c

Gaschard, M., Nehzat, F., Cheminel, T., and Therrien, B. (2018). Arene ruthenium metalla-assemblies with anthracene moieties for PDT applications. Inorganics 6, 97-113. doi: 10.3390/inorganics6030097

Gupta, G., Das, A., Panja, S., Ryu, J. Y., Lee, J., Mandal, N., et al. (2017). Self-assmbly of novel thiophene-based BODIPY $\mathrm{Ru}^{\mathrm{II}}$ rectangles: potential antiproliferative agents selective against cancer cells. Chem. Eur. J. 23, 17199-17203. doi: 10.1002/chem.201704368

Gupta, G., Oggu, G. S., Nagesh, N., Bokara, K. K., and Therrien, B. (2016). Anticancer activity of large metalla-assemblies built from half-sandwich complexes. CrystEngComm 18, 4952-4957. doi: 10.1039/c6ce00139d

Haviv, E., Azaiza-Dabbah, D., Carmieli, R., Avram, L., Martin, J. M. L., and Neumann, R. (2018). A thiourea tether in the second coordination sphere as a binding site for $\mathrm{CO}_{2}$ and a proton donor promotes the electrochemical reduction of $\mathrm{CO}_{2}$ to $\mathrm{CO}$ catalyzed by a rhenium bipyridinetype complex. J. Am. Chem. Soc. 140, 12451-12456. doi: 10.1021/jacs.8b 05658

Hosseini, M. W. (2003). Molecular tectonics: from molecular recognition of anions to molecular networks. Coord. Chem. Rev. 240, 157-166. doi: $10.1016 / 50010-8545(03) 00021-3$

Kato, T., Uchida, J., Ichikawa, T., and Sakamoto, T. (2018). Functional liquid crystals towards the next generation of materials. Angew. Chem. Int. Ed. 57, 4355-4371. doi: 10.1002/ange.201711163

Linares, F., Galindo, M. A., Galli, S., Romero, M. A., Navarro, J. A. R., and Barea, E. (2009). Tetranuclear coordination assemblies based on half-sandwich ruthenium(II) complexes: noncovalent binding to DNA and cytotoxicity. Inorg. Chem. 48, 7413-7420. doi: 10.1021/ic900980y
Linares, F., Procopio, E. Q., Galindo, M. A., Romero, M. A., Navarro, J. A. R., and Barea, E. (2010). Molecular architecture of redox-active half-sandwich $\mathrm{Ru}(\mathrm{II})$ cyclic assemblies. Interactions with biomolecules and anticancer activity. CrystEngComm 12, 2343-2346. doi: 10.1039/C002411B

Mattsson, J., Zava, O., Renfrew, A. K., Sei, Y., Yamaguchi, K., Dyson, P. J., et al. (2010). Drug delivery of lipophilic pyrenyl derivatives by encapsulation in a water soluble metalla-cage. Dalton Trans. 39, 8248-8255. doi: $10.1039 / \mathrm{c} 0 \mathrm{dt} 00436 \mathrm{~g}$

Mishra, A., Ravikumar, S., Song, Y. H., Prabhu, N. S., Kim, H., Hong, S. H., et al. (2014). A new arene-Ru based supramolecular coordination complex for efficient binding and selective sensing of green fluorescent protein. Dalton Trans. 43, 6032-6040. doi: 10.1039/c3dt53186d

Mishra, A., Vajpayee, V., Kim, H., Lee, M. H., Jung, H., Wang, M., et al. (2012). Self-assembled metalla-bowls for selective sensing of multi-carboxylate anions. Dalton Trans. 41, 1195-1201. doi: 10.1039/c1dt11612f

Patrice, T., Moor, A. C. E., Ortel, B., and Hasan, T. (2003). "Mechanism of photodynamic therapy," in Photodynamic Therapy, ed T. Patrice (Cambridge, UK: The Royal Society of Chemistry), 19-58.

Paul, L. E. H., Therrien, B., and Furrer, J. (2012a). Investigation of the reactivity between a ruthenium hexacationic prism and biological ligands. Inorg. Chem. 51, 1057-1067. doi: $10.1021 /$ ic2021935

Paul, L. E. H., Therrien, B., and Furrer, J. (2012b). Interaction of a ruthenium hexacationic prism with amino acids and biological ligands: ESI mass spectrometry and NMR characterisation of the reaction products. J. Biol. Inorg. Chem. 17, 1053-1062. doi: 10.1007/s00775-012-0918-8

Paul, L. E. H., Therrien, B., and Furrer, J. (2015). Reactivity of hexanuclear ruthenium metallaprisms towards nucleotides and a DNA decamer. J. Biol. Inorg. Chem. 20, 49-59. doi: 10.1007/s00775-014-1208-4

Paul, L. E. H., Therrien, B., and Furrer, J. (2018). The complex-in-a-complex $\left[\mathrm{Pt}(\mathrm{acac})_{2} \subset(p \text {-cym })_{6} \mathrm{Ru}_{6}(\mathrm{tpt})_{2}(\mathrm{dhnq})_{3}\right]^{6 \pm}$ : Its stability towards biological ligands. Inorg. Chim. Acta 469, 1-10. doi: 10.1016/j.ica.2017.08.045

Piotrowski, H., Polborn, K., Hilt, G., and Severin, K. (2001). A self-assembled metallomacrocycle ionophore with high affinity for $\mathrm{Li}^{+}$and $\mathrm{Na}^{+}$. J. Am. Chem. Soc. 123, 2699-2700. doi: 10.1021/ja005804t

Schmitt, F., Freudenreich, J., Barry, N. P. E., Juillerat-Jeanneret, L., SüssFink, G., and Therrien, B. (2012). Organometallic cages as vehicles for intracellular release of photosensitizers. J. Am. Chem. Soc. 134, 754-757. doi: $10.1021 / \mathrm{ja} 207784 \mathrm{t}$

Schmitt, F., Govindaswamy, P., Süss-Fink, G., Ang, W. H., Dyson, P. J., Juillerat-Jeanneret, L., et al. (2008). Ruthenium porphyrin compounds for photodynamic therapy of cancer. J. Med. Chem. 51, 1811-1816. doi: $10.1021 /$ jm701382p

Schmitt, F., Govindaswamy, P., Zava, O., Süss-Fink, G., Juillerat-Jeanneret, L., and Therrien, B. (2009). Combined arene ruthenium porphyrins as chemotherapeutics and photosensitizers for cancer therapy. J. Biol. Inorg. Chem. 14, 101-109. doi: 10.1007/s00775-008-0427-y

Singh, A. K., Pandey, D. S., Xu, Q., and Braunstein, P. (2014). Recent advances in supramolecular and biological aspects of arene ruthenium(II) complexes. Coord. Chem. Rev. 270-271, 31-56. doi: 10.1016/j.ccr.2013.09.009

Steed, J. W. (2001). First- and second-sphere coordination chemistry of alkali metal crown ether complexes. Coord. Chem. Rev. 215, 171-221. doi: $10.1016 / 50010-8545(01) 00317-4$

Therrien, B. (2009). Arene ruthenium cages: Boxes full of surprises. Eur. J. Inorg. Chem. 2445-2453. doi: 10.1002/ejic.200900180

Therrien, B. (2015). Biologically relevant arene ruthenium metalla-assemblies. CrystEngComm 17, 484-491. doi: 10.1039/c4ce02146k

Therrien, B. (2018). Arene ruthenium complexes in supramolecular chemistry. Adv. Inorg. Chem. 71, 379-402. doi: 10.1016/bs.adioch.2017.11.008

Therrien, B., and Furrer, J. (2014). The biological side of water-soluble arene ruthenium assemblies. Adv. Chem. 2014:589686. doi: 10.1155/2014/589686

Therrien, B., Süss-Fink, G., Govindaswamy, P., Renfrew, A. K., and Dyson, P. J. (2008). The "complex-in-a-complex" cations $\left[(\mathrm{acac})_{2} \mathrm{M} \subset \mathrm{Ru}_{6}(p-\right.$ $\left.\left.i \mathrm{PrC}_{6} \mathrm{H}_{4} \mathrm{Me}\right)_{6}(\mathrm{tpt})_{2}(\mathrm{dhbq})_{3}\right]^{6 \pm}$ : A Trojan horse for cancer cells. Angew. Chem. Int. Ed. 47, 3773-3776. doi: 10.1002/anie.200800186

Vajpayee, V., Song, Y. H., Lee, M. H., Kim, H., Wang, M., Stang, P. J., et al. (2011). Self-assembled arene-ruthenium-based rectangles for the selective sensing of multi-carboxylate anions. Chem. Eur. J. 17, 7837-7844. doi: 10.1002/chem.201100242 
Wu, B., Liang, J., Yang, J., Jia, C., Yang, X.-J., Zhang, H., et al. (2008). Sulfate ion encapsulation in caged supramolecular structures assembled by second-sphere coordination. Chem. Commun. 1762-1764. doi: 10.1039/b719019k

Zhao, J., Bacolla, A., Wang, G., and Vasquez, K. M. (2010). Non-B DNA structureinduced genetic instability and evolution. Cell. Mol. Life Sci. 67, 43-62. doi: 10.1007/s00018-009-0131-2

Zhou, J., Yu, G., and Huang, F. (2017). Supramolecular chemotherapy based on host-guest molecular recognition: a novel strategy in the battle against cancer with a bright future. Chem. Soc. Rev. 46, 7021-7053. doi: 10.1039/c6cs0 0898d
Conflict of Interest Statement: The author declares that the research was conducted in the absence of any commercial or financial relationships that could be construed as a potential conflict of interest.

Copyright (c) 2018 Therrien. This is an open-access article distributed under the terms of the Creative Commons Attribution License (CC BY). The use, distribution or reproduction in other forums is permitted, provided the original author $(s)$ and the copyright owner(s) are credited and that the original publication in this journal is cited, in accordance with accepted academic practice. No use, distribution or reproduction is permitted which does not comply with these terms. 